\title{
Recruitment of South Asians into asthma research: qualitative study of UK and US researchers
}

\section{Lucy Stirland", Laila Halani ${ }^{b}$, Bhopal Raj', Gopalakrishnan Netuveli ${ }^{\text {, }}$ Martyn Partridge $e^{e}$ Josip Car ${ }^{\mathrm{d}}$, Chris Griffiths ${ }^{\mathrm{f}}$, Mark Levy ${ }^{\mathrm{b}},{ }^{*}$ Aziz Sheikh ${ }^{\mathrm{b}}$}

\author{
a Foundation Doctor, Ninewells Hospital, Dundee, Scotland, UK \\ ${ }^{b}$ Allergy \& Respiratory Research Group, Centre for Population Health Sciences, The University of Edinburgh, Edinburgh, UK \\ ' Ethnicity and Health Research Group, Centre for Population Health Sciences, The University of Edinburgh, Edinburgh, UK \\ 'Primary Care and Social Medicine, Imperial College, London, UK \\ e NHLI Division at Charing Cross, Imperial College, London, UK \\ ${ }^{f}$ Centre for Health Sciences, Barts and the London Queen Mary, London, UK
}

Originally received 4th December 2010; revised 22nd January 2011; accepted 27th January 2011; online 20th April 2011

\begin{abstract}
Background: There is increasing international concern about the persistent under-representation of ethnic minority patients in research. Aims: We aimed to explore strategies being employed by US and UK researchers when attempting to recruit minority ethnic participants into research with a view to increasing participation by South Asians in UK asthma research.

Methods: Qualitative interviews with 36 asthma-interested researchers.

Results: Key themes were: the need to build long-term trusting relationships; ensuring that the procedures and practices used were respectful; paying attention to logistic considerations with respect to funding, the location of the research and taking proactive steps to overcome language-related barriers; and the importance of effective dissemination of results to, amongst others, the minority ethnic groups under study. The use of financial incentives or "co-payments" was reported as being a successfully-employed strategy in the US context, which could be considered for use in the UK.

Conclusions: There is a need for funders and researchers to take proactive steps to develop longer-term relationships built on trust and respect with the populations they wish to study. Attention to the location of research, language considerations, financial reimbursement and appropriate dissemination of results are all likely to translate into improved recruitment of these "hard-to-reach" populations.

(C) 2011 Primary Care Respiratory Society UK. All rights reserved.

L Stirland et al. Prim Care Respir J 2011; 20(3): 282-290

http://dx.doi.org/10.4104/pcrj.2011.00032
\end{abstract}

Keywords asthma, ethnic minorities, recruitment, research participation

\section{See linked editorial by Johnson on pg 229}

The full version of this paper, with online Appendices,

is available at www.thepcrj.org

\section{Introduction}

People from minority ethnic groups are under-represented in United Kingdom (UK) research, and this problem is particularly prevalent in the field of asthma where health inequalities between ethnic groups are striking. ${ }^{1}$ This under-representation of ethnic minorities may be due to a range of practical difficulties encountered by researchers and/or may be a consequence of their deliberate exclusion. ${ }^{2}$ As well as carrying ethical and legal implications - as per the Race Relations (Amendment) Act $2000^{3}$ and Equality Act 2010 - a discrepancy is likely to affect adversely the external validity of study findings. Previous work has found that United States of America (US) studies are considerably more likely to report the ethnicity of candidates than European ones $(62.9 \%$ versus $2.9 \% ; p<0.0001),{ }^{5}$ these differences being even more striking

\footnotetext{
* Corresponding author: Professor Aziz Sheikh, University of Edinburgh, Centre for Population Health Sciences, Teviot Place, Edinburgh, Scotland, EH8 9AG, United Kingdom. Tel: +44 (0)1316514151 E-mail: aziz.sheikh@ed.ac.uk
} 
in the context of asthma trials. ${ }^{6}$ A key factor contributing to these differences is the impact of the 1993 National Institutes of Health $(\mathrm{NIH})$ policy stating that clinical research funded by the $\mathrm{NIH}$ must include a representative proportion of people from minority ethnic backgrounds; we have reported on the importance of this policy difference elsewhere. ${ }^{7.8}$ Whilst undoubtedly important, this is unlikely to be the only factor explaining these differences, as suggested by our study comparing the impact on ethnicity reporting in studies funded by the $\mathrm{NIH}$ and other US funders which are not bound by the same regulations on recruiting women and minority ethnic groups. ${ }^{9}$

In order to progress understanding on this issue, there is a need to understand more fully the experiences, views and concerns of researchers and patients. In this paper, we focus on the perspectives of academics with an interest in asthma drawn from both the US and UK. We enquired about the barriers they face in recruitment and the strategies they have (successfully or otherwise) employed in overcoming these. This study focuses on South Asians as the largest minority ethnic group in the UK, accounting for approximately $50 \%$ of the UK's minority ethnic population and $4 \%$ of the total UK population. ${ }^{10}$ In contrast, approximately $3 \%$ of the minority ethnic population of the US is of South Asian origin, making up $0.7 \%$ of the total population. ${ }^{11}$ This paper builds on earlier reports from our study focusing on the policy level differences between the US and UK, ${ }^{8}$ and the perspectives of UK South Asian patient/carer perspectives on barriers and facilitators to asthma research. ${ }^{12}$

\section{Methods}

\section{Study design}

In-depth interviews were conducted with asthma researchers from the UK and the US. Multi-centre research ethics committee and local research governance approvals were obtained, and all participants gave their informed consent to participate.

\section{Sampling and recruitment procedures}

A database of researchers was compiled by contacting experts and conducting a search of principal investigators on asthma projects undertaken or funded between 2001-2006 listed in Medline, the NIH database, the UK National Research Register, Asthma UK, and the Cochrane Airways Group. US and UK researchers were purposefully selected to identify researchers from diverse but relevant disciplinary backgrounds: i.e. genetics, basic sciences, epidemiology, statistics, primary and secondary care, and quantitative and qualitative research. When sampling, we also considered researchers' likely experiences of recruiting and working with minority ethnic people, based on published reports, to ensure that we recruited at least some participants who could draw on their previous experiences.

\section{Data generation}

Interviews with researchers were conducted either face-toface or by telephone by a social anthropologist with considerable experience of conducting qualitative field work. Interviews lasted 15-60 minutes and a topic guide derived from key findings in the literature (Appendix 1, available online at www.thepcrj.org) was used as a prompt, if necessary. Interviews were digitally recorded and transcribed in full; interviewees were offered a copy of the transcript to check. Participants were assured anonymity in order to encourage them to speak freely on a potentially sensitive subject.

\section{Data analysis}

Data analysis occurred as an ongoing process throughout data generation thereby allowing issues raised by participants to be fed into future interviews and continued until after data collection had ceased. 13 The study researcher and principal investigator met weekly to discuss the findings from interviews and considered the data and our evolving interpretations of these at regular intervals with members of the wider multi-disciplinary project steering group. We attempted to remain abreast of key developments in the literature, thereby allowing these issues to be discussed and also to allow our findings to be understood in the context of this broader literature. ${ }^{14}$

Data were analysed using the Framework approach, a method developed for social policy research and particularly suited to large data sets. ${ }^{15}$ This involved the following key stages:

i. familiarisation with the data

ii. identification of a thematic framework

iii. indexing and annotating of transcripts with a set of descriptors

iv. charting, and where necessary, rearranging the data according to category (see Appendices 2 and 3, available online at www.thepcrj.org), and

v. mapping and interpretation thereby allowing the linking of themes and analysing their possible explanations.

We actively sought out alternative explanations and remained aware of the need to be reflexive with respect to our own backgrounds and experiences when analysing and interpreting these data. ${ }^{16}$ Data collection continued until saturation, i.e. the point at which no major new ideas were emerging.

\section{Results}

A total of 43 (21 UK, 22 US) invitations were sent out to asthma researchers. Four (2 UK, 2 US) of those invited failed to respond and a further three (US) declined. We therefore had a total of 36 (19 UK, 17 US) participants. Eleven (9 UK, 2 US) interviews were conducted face-to-face, the remainder being conducted by telephone. Researchers were recruited from a range of 
L Stirland et al.

\section{Table 1. Disciplines of asthma researchers}

\begin{tabular}{|c|c|}
\hline Researcher No. & Discipline \\
\hline R01 & Sociologist \\
\hline R02 & Respiratory consultant \\
\hline R03 & Social scientist \\
\hline R04 & Primary care \\
\hline R05 & Environmental and occupational medicine \\
\hline R06 & Primary care \\
\hline R07 & Basic scientist, immunologist \\
\hline R08 & Respiratory consultant and journal editor \\
\hline R09 & Allergy and immunology physician \\
\hline R11 & Primary care \\
\hline R12 & Primary care \\
\hline R13 & Primary care \\
\hline R14 & Primary care \\
\hline R15 & Epidemiologist \\
\hline R16 & Respiratory physician and journal editor \\
\hline R17 & Health policy and health education \\
\hline R18 & Social scientist \\
\hline R19 & Epidemiologist \\
\hline R20 & Epidemiologist, basic scientist, geneticist \\
\hline R21 & Social scientist \\
\hline R22 & Basic scientist \\
\hline R23 & Epidemiologist \\
\hline R24 & Geneticist \\
\hline R27 & Basic scientist, epidemiologist \\
\hline R29 & Statistician \\
\hline R30 & Primary care \\
\hline R35 & Epidemiologist, health educationist \\
\hline R37 & Sociologist, behavioural scientist \\
\hline R38 & Epidemiologist, statistician \\
\hline R39 & Translational scientist \\
\hline R40 & Clinical professor \\
\hline R41 & Basic scientist \\
\hline R42 & Pharmacist, health economist, editor \\
\hline R43 & Health educationist, qualitative researcher \\
\hline R44 & Basic scientist \\
\hline R45 & Psychologist, educationist \\
\hline
\end{tabular}

Apart from the three social scientists (who were chosen due to their interest and works on ethnicity and health research), all the interviewees have worked and published on asthma.

Identifiers have been kept to a minimum to avoid the risk of inadvertent disclosure of identity.

disciplinary backgrounds (see Table 1).

Interviewees discussed their views on recruiting people from ethnic minority backgrounds into research studies and the barriers they believed are contributing to this underrepresentation of minority ethnic groups. They shared their experiences of effective strategies for increasing participation

\section{Box 1: Key findings}

- The need to build long-term trusting relationships

- Ensuring that the approaches and procedures used are, and are seen to be, respectful of the community's and individuals' values

- Careful attention to a number of key logistic considerations during study planning and execution including the location of the research, securing funding for translation, interpretation and reimbursing gatekeepers and participants, flexibility and persistence.

- Effective dissemination of findings to peers, but crucially also to the minority ethnic populations themselves.

amongst ethnic minority communities and their ideas for potential future methods of overcoming barriers to inclusion. Some of these methods reinforced recruitment strategies that have been identified in studies conducted in other disease contexts, ${ }^{1-24}$ whereas others have not, as far as we are aware, been previously reported. There was a marked difference between researchers' experiences in the two countries: in the US far more interviewees had worked with people from ethnic minorities and had developed strategies to do so effectively and efficiently, whereas in the UK there was a marked lack of exposure to, and hence engagement, with the issue. Box 1 summarises the key themes identified, which are then discussed in more depth below.

\section{Trusting relationships}

\section{a) Community organisations and leaders}

A frequently recommended strategy for earning the trust of potential study participants was ongoing involvement with community groups, community leaders and faith organisations. Researchers who had previously liaised with organisations, whether in the context of research or indeed in any other context, found it relatively easy to know both who to approach and also how to forge an effective relationship with these communities. Involving groups early on in the research process also helped to cultivate a sense of ownership of the project. One researcher reported employing community leaders as research personnel, whilst others described communicating through a link person who acted as an ambassador between the community and investigators:

"Because I myself am not an African-American person...

I have co-investigators and colleagues who know the

community well and who are trusted in the community"

R02, US

Most researchers thought this person should be from the 
community in question, but this could and at times did raise potentially important issues in relation to ensuring confidentiality; this needed to be taken into account:

"That might put them off because the other thing with a lot of Asian people, if they know you're from the community they're going to say "Oh you're going to gossip"... it is a social thing but I think it's more of a cultural thing... "but what would the neighbours say?" You know that kind of thing." R03, UK

Personal contact with community leaders and/or elders was described as essential by those with positive previous experiences of recruiting minority participants. Such a personal relationship, if cultivated, could be an antidote to the problem of possible "research fatigue" experienced by some members of their community or faith groups. Penetration of collaborations of community groups and/or national organisations was also raised as being potentially important - since this could facilitate entry into related organisations and hence participants in other geographical regions or age groups. Finding mutually beneficial arrangements for researchers and community/faith groups was advocated; suggested examples included buying advertisements in community newsletters/publications and hiring rooms in community/religious centres in which to hold meetings and/or assess research participants. More direct approaches were also cited. For example, one US researcher reported giving a financial gift to a church in return for help with recruitment.

Conversely, participants also reported instances where consultation with or work on minority ethnic communities was perceived by the communities themselves as being conducted in a tokenistic fashion, these adverse experiences having a negative impact on relationships with the research community with knock-on implications for future studies.

\section{b) Schools and family involvement}

Schools can be a helpful and trusted link in areas with large numbers of ethnic minority people, especially where health services are already present in schools. Researchers reported that teachers and school staff (including nurses) were often willing to help recruit their students for studies if approached sensitively. Staff were also cited as a valuable resource for not only understanding how best to approach the target age group, but for practical issues such as translation. However, one participant reported that when a school nurse was the sole representative of a study in a school, recruitment was lower than when research staff were also physically present.

Incentives for participation could be aimed not only at students for responding to invitations, but also towards the school - such as small gifts of classroom materials for a poorly resourced school. However, there were potential concerns raised about the giving of gifts directly to students, since unless chosen carefully these could promote rivalry and peer pressure to participate. Whilst the importance of adequate consent procedures was taken 'as read', some researchers noted the particular importance of involving other family members in the consent process when recruiting minority ethnic children:

"In some cultures... if I want to do something I'm part of

a family group and I maybe need to get at least the tacit approval of the group." R04, UK

\section{c) Communication and transparency}

Effective communication was another suggested attribute of a successful recruitment programme. A recurring theme in the interviews was that when potential participants fully understand the work being carried out they engage better to, and are more likely to respond positively to, invitations. Some distrust towards researchers, especially in the US, appeared to be tied-up with a suspicion that research professionals are in some way linked to either the authorities or hospital debt collectors. If these fears are dispelled and the need for more inclusive representation and the benefits of participation for both individuals and society at large explained, then people were more likely to be willing to take part:

"Maybe if you could explain that it's an asthma trial, asthma outcomes are poor in your population group and yes, one of the reasons maybe is because people from your ethnic group haven't taken part in the research, so we haven't come to understand the particular needs..." R06, UK

\section{d) Personal touch}

A personal approach, including face-to-face contact, was seen as instrumental to building relationships between research staff and members of ethnic minority communities. Some researchers reported this process taking several years and that telephone contacts were the best method of maintaining a rapport once a relationship had been forged. One recommended giving participants the researcher's personal phone number so they could be contacted with any queries. The involvement of clinicians whom patients already know, particularly family doctors, was repeatedly commended as this too could help develop trust. This long-term personalised relationship building allowed a tacit understanding of community values and orientation to emerge, which in turn gave the researchers greater licence and confidence to engage with the communities in an organic, mutually enriching way:

"I think that if... you recognise what you don't know, you're respectful of the community, you're comfortable in the community and you're actually doing research in the community, we always did pretty well recruiting patients." R43, US

However, a topic that frequently arose was the difficulty in accessing the potentially valuable support of primary care providers. Interviewees felt that, in particular, UK GPs often did not have the time, training or financial incentives to support recruitment. It was also mentioned that in some minority ethnic 
communities where the population is transient, GPs are not a practical gateway to patients. One UK researcher described several GP practices joining together to employ a research assistant who could then personally support the recruitment effort.

\section{Respect}

\section{a) Incentives and reimbursement}

The most commonly mentioned strategy for improving recruitment rates was financial reimbursement for participants' time, this being raised in almost half of the interviews. This is an area where marked differences between the US and UK were apparent; for example, US researchers described the appropriateness of "co-payment" for patients' medications in return for their taking part in a study, giving free general health screenings or offering services such as spirometry to clinics that might not otherwise have the opportunity to use them. US researchers reported the use of vouchers that could be used to purchase food or other essentials, but they also reported instances in which they had paid subjects by cheque (which was acceptable to the funding bodies sponsoring the research); these payments, whether in kind or in cash, were regarded as important as these served as a practical demonstration that people's time was valued.

Problems raised with such incentives included the exclusion of those with higher incomes for whom a financial incentive was less attractive, and the acceptance of an incentive, but then a reluctance to participate meaningfully (for example, in a focus group discussion). Abuses of these incentives were also reported - for example, people lying about their condition in order to meet the eligibility criteria and then using the payments to buy large amounts of alcohol.

There was more convergence between the US and UK when it came to reimbursing patients for travel expenses and offering snacks or a meal if the intervention took place over a meal time, both of which were common practices. Covering child care costs or providing on-site activities for children was reported as effective when working with families.

One US researcher discussed the value of holding community events such as barbecues or family activity days to publicise the work being carried out. Another interviewee with particular experience working in schools threw pizza parties for the class that had the highest response rate to invitations to participate (whether positive or negative). American hospitals or health centres were willing to be approached to fund these sorts of initiatives, but local businesses had also agreed to contribute, this latter approach perhaps being more applicable within a UK context. US funding bodies (including the $\mathrm{NIH}$ ) were willing to allow budgeting for these "extra costs" of recruiting people from ethnic minorities, including reimbursement for their time; a willingness to cover the more traditional costs such as for translation was reported as being more broadly acceptable to both UK and US funders.

\section{b) Cultural and religious sensitivity}

The broad, but vital issue of cultural and religious sensitivity was broached in many of the interviews. Attention to detail can help promote trust and generate respect for researchers as well as facilitating a smooth study experience. Examples mentioned included holding gender-specific interviews and focus groups where appropriate, being prepared to accept and document verbal consent, and only entering a participant's home when accompanied by a community member. Some researchers highlighted attention to specific religious norms - for example not sending male staff to interview unaccompanied young Muslim women. One strategy mentioned which worked around this was a researcher taking his wife with him on field visits. It was advised that information material be clear and comprehensive to minimise the impact of studying possibly stigmatising conditions (including asthma). Careful communication was hailed as a key approach to fostering good relations, which would allow understanding between researchers and study participants of issues where important cultural differences might exist:

"And you explain to them why and then you say "can you

help me now? I don't know a lot about Sri Lanka. I've

never been there, I don't know anybody from Sri Lanka.

could you help me understand?" R12, US

This was seen as working best when techniques were employed to help staff appreciate and understand principles of engagement rather than a set of rules. Flexibility was important so that different communities' needs could be catered for without the use of stereotypes; the sometimes unfamiliar health beliefs of people from different communities could then be respected.

\section{Logistic considerations a) Language}

Language issues were a major contributor to difficulties faced by researchers, both in the US and UK. A lack of time and resources for translating material was widely recognised as a reason for excluding minority people. Conversely, simply translating the invitation letter into several languages dramatically increased one researcher's response rate:

"People were quite happy filling in the English instrument but they wanted a letter in there in their own language. And it was interesting as all we did... was just literally put several versions of the same letter in the envelope." R11, UK

The importance of questionnaires ideally being validated in other languages or at least trialled by some members of the community was emphasised. The difficulties posed by not having suitably validated instruments in the required language(s) were also highlighted, since this could in effect bar use of these questionnaires and by extension their enrolment in the study. Some researchers proposed the idea that a national resource 
bank should be formed, allowing researchers to share translation materials and contacts and encouraging the improvement of translation facilities. A database of asthma patients including their ethnicity would, it was suggested, also be useful for recruiting into large-scale studies. On a more individual level, a technique that many researchers used was to employ a member of research staff who could speak the language of the community in question and could help not only with direct translation but also in building trust:

"As long as there is someone around that speaks their

language and they feel comfortable, that spreads

beyond, the rest of us get extra credit - they're more

comfortable with us because they see that we've taken

the effort" R41, US

It was also noted that ideally the researcher should be fluent in the language and have specialist knowledge so that they could explain technical details of the trial - for example, how to use equipment/inhalers.

\section{b) Advertising}

The use of appropriate languages was recommended for advertising - for example, using multilingual posters or providing spoken study information on CD or DVD - which would also be suitable for use in communities with predominantly oral cultures. The use of symbols was suggested to ensure the inclusion of people who are functionally illiterate. It was emphasised that translations should be thorough and culturally appropriate, and that interpreters may need specialist skills to clearly explain complex clinical procedures.

Other suggested methods to make advertising more effective included targeting the adverts at certain communities for example, advertising on a radio station aimed at Asian listeners. Posters featuring photos of minority ethnic people placed in community centres or places of worship had proven effective, and one researcher suggested asking well-known people from the South Asian community to endorse studies.

\section{c) Geographical location and convenience}

A potentially important and effective method of increasing recruitment that has not yet really been discussed in the published literature was targeting a geographical area with a high concentration of people from ethnic minorities. Holding studies in these areas and ensuring easy accessibility would (it was suggested) improve response rates. A number of US (but not UK) researchers were factoring such deliberations into their funding proposals:

"We make sure that access to the study clinic is very easy so don't put it in the middle of a big hospital complex where they have to pay for parking and... the bus stop is 4 blocks away and everything. Put it in a suburban shopping mall or some place that's right next to the bus stop or tube stop... [so] they can just walk right in." R38, US
Some interviewees emphasised that meeting patients in a place where they feel safe and confident such as hired rooms in a community centre or working alongside a local GP in their practice building can help foster trust as well as providing easy access. Researchers said that if the study centre could not be moved to a convenient place then they arranged transport or reimbursement for travel costs. Offering to work with patients at a time that suits them, such as evenings or weekends, also increased recruitment and retention.

\section{d) Persistence}

The importance of persistence was another effective technique highlighted by US researchers that has again not previously been discussed in the literature. Examples cited included repeated phone calls to remind participating clinicians to ask their patients to consider enrolling in a study and, more commonly, direct contact with potential subjects. This included telephone contact and visiting them at home. Researchers reported that in some communities it can be hard to reach patients by telephone, especially if they are frequently relocating. One suggested approach to this problem was to ask for multiple telephone numbers, but clearly this was only really appropriate after a certain degree of trust has already been established:

"We have learned after our first couple of studies we get no fewer than 10 phone numbers from these patients, including relatives, places they might [be]... we ask about pagers, cell phones... We just say, you know, "We want to be able to contact you no matter where you go." R37, US

\section{Recommendations throughout the research process, and dissemination}

Some researchers suggested that the involvement of people from ethnic minority backgrounds should be considered right from the outset of the research process. The design stage was mentioned as a key point at which to begin engaging with community groups and developing a sense of shared ownership of the project. Some reported that US funding bodies accepted the extra costs involved in recruiting people from ethnic minorities, such as for translation and employing specific members of staff. The recruitment stage was seen as the time when researchers can draw on relationships already forged with local communities to work with them and through so doing gain respect and trust. Some US researchers also reported addressing logistical issues such as translating materials and considering oral consent at an early stage in the project's gestation. It was noted that a well-developed understanding of the community allows staff to be culturally sensitive throughout the data collection process. There was a need expressed throughout the research process for researchers to challenge existing negative stereotypes and misconceptions so as not to derail efforts at trying to engage with these communities. Active and open discussion and debate were seen as important in this respect: 
"We had small group discussions and you could see, sort of having the debate that happens in small groups and then start letting people open it up... but then after that you could have people giving ... 20 minute presentations on how they work with a specific minority in a specific area and they try to take those and generalise them to broad concepts." R12, US

Once completed, the sharing of results back to participants was also seen as demonstrating the value of their contribution, which could in turn lay the foundation for future collaborative ventures. Researchers recommended publishing work on recruitment and ethnic minorities in widely-read journals to raise awareness of these issues among the research community. The importance of training the research fraternity in diversity considerations was also emphasised.

\section{Discussion}

This study has uncovered a wealth of techniques already in place or being considered for promoting more representative recruiting into asthma studies. ${ }^{8,12}$ Of particular interest is the range of (as yet) untried approaches in the UK being employed in the US, perhaps most important of all in the short-term being the issue of reimbursing participants for their time. However, concerns have been raised about this method since potentially it could lead to the exploitation of those on lower incomes, ${ }^{25}$ so such an approach, if considered appropriate to use in the UK, would need to be implemented with considerable care.

Some of the techniques mentioned in interviews have also been described in relation to the literature in other disease areas. A UK study exploring the views of South Asians about research recommended providing translated study information or audio or video recordings, as well as advertising on Asian radio stations or with posters in community centres, GP surgeries or cultural events (Melas). ${ }^{17}$ Similarly, a large Department of Health drug misuse project advertised in the local and national press, and by sending flyers to minority ethnic community centres; they also tried to cultivate a sense of ownership of the project among people from the communities being studied by recruiting community representatives to carry out the work and hold local events. ${ }^{21}$ One study's method for trying to formulate a shared vision was to involve the community at an early stage and then to share the results with participants when the study concluded. ${ }^{22}$ Involvement with community groups, faith organisations and community leaders is also seen as an important method for trying to improve recruitment, ${ }^{18,19,26}$ as is community outreach. ${ }^{23}$ This could perhaps be extended to the involvement of people from relevant minority ethnic communities in ethics committee deliberations so that a culturally-sensitive approach could be introduced from the design stage.

\section{Strengths and limitations of this work}

The inclusion of researchers from the US and the UK coming from disparate backgrounds was an important strength of our approach. The findings generated built on and extended the findings of previous work in this area, thereby suggesting novel approaches that could be employed, particularly in the UK, to try and bolster researchers' experience and in due course expertise in working with relatively unfamiliar population groups and also to make research more acceptable to the minority communities themselves. That the findings from this work resonate with other key developments in the broader ethnicity literature, such as the need for proactive consultation with minority groups, the importance of effective inter-cultural communication, ${ }^{27,28}$ staff receiving cultural awareness and sensitivity training, ${ }^{20}$ and the involvement of community groups and link workers, are additional strengths of this work. ${ }^{29}$ Any changes in legislation should be consistent with current policy to maximise efficacy, particularly with the Race Relations Amendment Act and Equality Act. ${ }^{30}$

Qualitative work always raises the issue of generalisability beyond the participants involved. In this case, due to the differing proportions and composition of ethnic minorities in US and UK populations - for example, the researchers' work with African American and Hispanic people - it may not be possible to apply some of the US-based approaches to South Asians in the UK. The clear differences between the US and UK health services also limits the extent to which US techniques may be effective in the UK. For example, healthcare-based incentives can have a considerable benefit to a US patient who does not have health insurance, whereas in the UK, where healthcare is free at the point of delivery, patients may not see the direct advantages. Not all recruitment methods mentioned allow for representative samples, such as working with young people in schools (who often have different language and cultural experiences from older generations, especially if they were born in the US or UK) and therefore they may not be representative of their ethnic group as a whole.

Many of the approaches we have been able to identify may be extrapolated to minority ethnic groups other than South Asians because the data from US researchers drew on experiences with Hispanic and African American populations that shared many of the same problems in recruitment as identified by UK researchers. Research involving other minority ethnic groups in the UK is likely to encounter common barriers to that with South Asian people; for example language issues. The researchers interviewed all had an interest in asthma and their comments reflected the need for sensitivity in what could potentially be a stigmatising condition. However, most of the techniques in use were not 
specific to asthma research and could (we believe) probably be employed in other disease areas.

\section{Implications of this work}

The importance of forming long-term relationships built on trust and mutual respect is fundamental to ensuring progress in trying to recruit more inclusively into studies, and this is likely to be most effectively and efficiently achieved in the UK by funders investing in regional specialist ethnicity hubs, which can then act as a resource to the entire research fraternity.

Our work has also identified the need to consider a range of important logistical considerations which should really be considered at the planning stage and then be costed into the study right from the outset; whilst some of these costs such as those relating to translation and interpretation services are likely to prove acceptable to UK funders, others relating to the provision of community events and funding for link workers are likely to be less familiar to reviewers and grant awarding panels and may therefore be looked at with a degree of suspicion. More controversially perhaps, this work has identified the need to consider co-payment for researcher time: the failure to offer to reimburse in this respect may be seen by the individuals concerned and their communities as in some way failing to appreciate their input; conversely, even token "payments" may be seen as valuing individual's time and input and may thus serve as a useful bridge to establishing more meaningful longterm relationships. However, such an approach is not without a number of important ethical challenges as well as obvious shortand possibly long-term funding implications for research funding bodies. Therefore, we believe it should not be extended to the UK in the absence of a more secure evidence base.

\section{Acknowledgements}

We are very grateful to the participants for sparing the time to share their views on this subject and also for their frankness in discussing a potentially sensitive subject.

\section{Conflicts of interest}

Aziz Sheikh is Joint Editor-in-Chief, Mark Levy is Emeritus Editor, Chris Griffiths is an Assistant Editor and Gopalakrishnan Netuveli is Statistical Editor of the PCRJ. None of these authors were involved in the editorial review of, nor the decision to publish, this paper.

\section{Contributorship}

AS conceived and was PI of this study supervising all aspects of project management, analysis and writing up. LS undertook data analysis and drafted the manuscript. LH undertook data collection and contributed to analysis. RB, GN, MP, JC, CG and ML were grant-holders and contributed to designing and interpreting data; they furthermore commented on drafts of the manuscript.

\section{Funding}

Asthma UK.

\section{References}

1. Netuveli G, Hurwitz B, Levy M, et al. Ethnic variations in UK asthma frequency, morbidity, and health-service use: a systematic review and meta-analysis. Lancet 2005;365:312-17.
2. Hussain-Gambles M, Leese B, Atkin K, Brown J, Mason S, Tovey P. Involving South Asian patients in clinical trials. Health Technol Assess 2004;8(42):iii,1-109.

3. Race Relations (Amendment) Act 2000. Available at: http://www.opsi.gov.uk/ acts/acts2000/ukpga_20000034_en_1 (last accessed 8th November 2010)

4. Equality Act 2010. Available at: http://www.legislation.gov.uk/ ukpga/2010/15/contents (last accessed 14th January 2011)

5. Sheikh A, Netuveli G, Kai J, Panesar SS, Comparison of reporting of ethnicity in US and European randomised controlled trials. BMJ 2004;329:87-8. http://dx.doi.org/10.1136/bmj.38061.593935.F7

6. Sheikh A, Panesar SS, Lasserson T, Netuveli G. Recruitment of ethnic minorities to asthma studies. Thorax 2004;59:634.

7. National Institutes of Health Policy and Guidelines on The Inclusion of Women and Minorities as Subjects in Clinical Research 2001. Available at: http://grants.nih.gov/grants/funding/women_min/guidelines_amended_10_20 01.htm (last accessed 8th November 2010)

8. Sheikh A, Halani L, Bhopal R, et al. Facilitating the recruitment of minority ethnic people into research: qualitative case study of South Asians and asthma. PLoS Med 2009;6:e1000148. http://dx.doi.org/10.1371/journal.pmed.1000148

9. Sheikh A, Panesar SS, Lasserson T, Netuveli G. Authors reply: Recruitment of ethnic minorities to asthma studies. Thorax 2005;60:257.

10. Census, April 1991 and 2001, Office for National Statistics; Census, April 2001, General Register Office for Scotland; Census, April 2001, Northern Ireland Statistics and Research Agency National Statistics Online: Population Size. http://www.statistics.gov.uk/cci/nugget.asp?id=455 (last accessed 7th January 2011)

11. U.S. Census Bureau American FactFinder Census 2000 Summary File 1100 Percent Data Detailed Tables Available at: http://factfinder.census.gov/servlet/ DatasetMainPageServlet?_program=DEC\&_submenuld=\&_lang=en\&_ts=Last accessed 7th January 2011

12. Rooney LK, Bhopal R, Halani L, et al. Promoting recruitment of minority ethnic groups into research: qualitative study exploring the views of South Asian people with asthma. J Public Health (Oxf). 2011 Jan 12. [Epub ahead of print]

13. Green J, Commentary: Grounded theory and the constant comparative method. BMJ 1998;316:1065.

14. Wendler $D$, Kington R, Madans J, et al. Are racial and ethnic minorities less willing to participate in health research? PLOS Med 2006;3:e19. http://dx.doi.org/10.1371/journal.pmed.0030019

15. Pope C, Ziebland S, Mays N. Analysing qualitative data. In Pope C, Mays N (Eds) Qualitative Research in Health Care 2nd Edition BMJ Books 2000.

16. Mauthner N, Doucet A. Reflexive accounts and accounts of reflexivity in qualitative data analysis. Sociology 2003;37:413-31. http://dx.doi.org/ 10.1177/00380385030373002

17. Hussain-Gambles M, Atkin K, Leese B. South Asian participation in clinical trials: the views of lay people and health professionals. Health Policy 2006; 77:149-65. http://dx.doi.org/10.1016/j.healthpol.2005.07.022

18. Areán PA, Gallagher-Thompson D. Issues and recommendations for the recruitment and retention of older ethnic minority adults into clinical research. J Consult Clin Psychol 1996;64:875-80. http://dx.doi.org/10.1037/0022006X.64.5.875

19. Brown DR, Fouad MN, Basen-Engguist K, Tortolero-Luna G. Recruitment and retention of minority women in cancer screening, prevention, and treatment trials. Ann Epidemiol 2000;10(8 Suppl):S13-21. http://dx.doi.org/10.1016/ S1047-2797(00)00197-6

20. Lloyd CE, Johnson MR, Mughal S, Sturt JA, Collins GS, Roy T, Bibi R, Barnett $\mathrm{AH}$. Securing recruitment and obtaining informed consent in minority ethnic groups in the UK. BMC Health Serv Res 2008;8:68. http://dx.doi.org/10.1186/1472-6963-8-68

21. Winters M, Patel K. Community Engagement Report 1: The Process. The Department of Health's Black and Minority Ethnic Drug Misuse Needs Assessment Project. University of Central Lancashire 2003. 
L Stirland et al.

22. Sin $\mathrm{CH}$. Sampling minority ethnic older people in Britain. Ageing \& Society 2004;24:257-77. http://dx.doi.org/10.1017/S0144686X03001545

23. Keyzer JF, Melnikow J, Kuppermann M, Birch S, Kuenneth C, Nuovo J, Azari R, Oto-Kent D, Rooney M. Recruitment Strategies for Minority Participation: Challenges and Cost Lessons from the POWER Interview. Ethnicity \& Disease 2005; 15:395-406.

24. Iqbal G, Gumber A, Szczepura A, Johnson MRD, Wilson S, Dunn JA. Improving ethnic data collection for statistics of cancer incidence, management, mortality and survival in the UK Report for Cancer Research UK, Coventry: Warwick Medical School Clinical Trials Unit 2008.

25. Goldacre B, The Unacceptable Face of Medical Research, The Guardian 23rd October 2010 Available at: http://www.guardian.co.uk/commentisfree/ 2010/oct/23/unacceptable-face-medical-research (Last accessed 14th November 2010)
26. Johnson MRD Involvement of black and minority ethnic consumers in health research Working Paper 3 Leicester: Mary Seacole Research Centre 2002

27. Arora S, Coker N, Gillam S, Ismail H. Improving the Health of Black and Minority Ethnic Groups: A guide for primary care organisations. King's Fund 2000.

28. Commission on the Future of Multi-Ethnic Britain. The Future of Multi-Ethnic Britain: the Parekh Report. Profile Books 2002 Chapter 21.

29. McGee $P$, Johnson MRD. Developing culturally competent services in palliative care: management perspectives in Gatrad R, Brown E, Sheikh A (Eds). Palliative Care for South Asians: Muslims, Hindus and Sikhs. Quay Books 2006.

30. Agulnik P, Burchardt T, Evans M. Response and Prevention in the British Welfare State in Hills J, Le Grand J, Piachaud D (Eds) Understanding Social Exclusion Oxford University Press 2002.

\section{Available online at http://www.thepcrj.org}


Ethnic minorities and asthma research

Appendix 1: Topic guide for interviews.

\section{Introductions}

- Particular interest or area of asthma research? (basic sciences, epidemiology, translational work, clinical/applied research)

- Experience of clinical/research work in US? UK? Elsewhere?

\section{Subject under study}

- Understanding of rationale for study

- Is the subject important? Why/why not?

- In what contexts might ethnicity considerations be most relevant?

\section{Experiences of recruiting minority ethnic people with asthma into studies}

- Ever considered the question of ethnicity of recruits into studies?

- Experiences of attempting to engage with minority ethnic communities, in particular South Asians.

- Are there barriers to recruiting South Asians that you have personally experienced or you are aware that other researchers have experienced? (Prompts: linguistic, cultural, religious, fear of falling foul, lack of interest, research fatigue, gatekeeper fatigue, obtaining informed consent, time, costs, irritated by political correctness)

- Are there strategies that you/others have successfully used in recruiting South Asians? (Prompts: location of study, minority ethnic co-researcher/research fellow, support of national/local community/religious organisations, financial)

\section{Reporting of data}

- When might ethnic specific reporting of data be relevant?

- Have you done this with previous studies? Why/why not?

- Are funders/journals interested?

\section{Next steps}

- Is more discussion, debate and consensus still needed?

- Response to recent research showing that minority ethnic people are equally likely to participate as Whites if invited to do so

- Is the US model of target setting a useful way forward?

- National initiatives that might help facilitate greater recruitment of South Asians?

- Actions that funding bodies/ethics committees/journals/researchers/ minority ethnic groups need to take?

- Anything else?

\section{Demographic characteristics of participant}

- Age

- Ethnicity

- Position

- Geographical location 
L Stirland et al.

Appendix 2: Coding framework with topics arranged in order of frequency.

Topic

Recompense participants with money, gift certificates

Mentioned in interview

Research colleagues from community being studied act as trusted link

R02, R07, R09, R14, R16, R27, R35,

$R 37, R 38, R 40, R 41, R 42, R 43, R 45$

R02, R06, R09, R11, R12, R16, R27,

$R 29, R 35, R 38, R 39, R 41$

Target people through relevant community groups

R01, R04, R06, R12, R16, R27, R29,

R35, R43, R03

$\mathrm{NIH}$ makes it compulsory to recruit ethnic minorities

R01, R02, R12, R16, R17, R27, R38,

$R 41, R 42$

Be flexible and tailor needs to individual communities

R02, R05, R07, R08, R16, R27, R29,

R43

Reimburse participants for travel expenses

R09, R16, R27, R37, R39, R41, R43,

R45

Recruit participants through faith organisations

R11, R16, R27, R29, R35, R37, R41,

R43

Long-term relationship building

$\overline{\mathrm{NIH}}$ demands relevant representative samples from communities

Translate information material

Approach community leaders to help with recruitment

Approach patients through their GPs

Provide childcare while patients are taking part in the study

Ensure translations are culturally appropriate

Develop understanding of cultural differences between researchers and community by communication

Employ fluent speakers who can understand and explain complex issues

Advertise in community-specific media

Specialised research employees who focus on recruitment

Fully explain what to expect from the study

Explain the benefits of participation

Find and use a link person within community

Meet people in their community's geographical area

Translate questionnaires

Rely on "snowballing"

Speak personally to invitees

Coordinator gets to know the participants personally

Provide services not otherwise available, eg bronchoscopy

Provide personal support in the language required, even if the participant speaks English

Translate consent form

Invite participants by telephone

Be culturally sensitive in recruitment

Combine data from different sites

$\mathrm{NIH}$ may withdraw funding if targets are not met

Explain the need for proportional representation

Provide incentives to subjects for participating

Consider involving other family members in consent process

Provide facilities for speakers of languages other than English

Validate questionnaires and documents

Explain the benefits of participation for the subjects' community

Persistence: repeated phone calls

It is difficult to get away from representing minorities

Private funding bodies may also penalise for excluding ethnic minorities

$\mathrm{NIH}$ guidelines on recruitment and representation work

Involve participants and community leaders at the design stage

Oral consent in the patient's language

$\mathrm{NIH}$ accepts provision for incentives within grant budgets

Recruit current participants for a subsequent study

Provide a meal for participants if they are needed for over an hour

Provide patients with their medication

Target younger members of a community

R02, R09, R27, R29, R35, R37

R02, R29, R37, R41, R42, R44

R04, R06, R07, R18, R20, R42

R04, R05, R12, R27, R29, R37

R03, R08, R11, R17, R23, R37,

$R 27, R 35, R 37, R 38, R 39, R 45$

R06, R16, R19, R38, R42

R11, R12, R18, R27, R35

R09, R11, R16, R38, R41

R01, R03, R07, R11, R35

R02, R07, R20, R27, R41

R02, R06, R07, R12, R29

R02, R06, R29, R35

R06, R09, R12, R35

R01, R35, R41, R43

R02, R04, R06, R45

R05, R12, R27, R37

R08, R15, R41, R45

R27, R38, R39, R43

R09, R27, R37, R38

R02, R04, R09, R16

R04, R20, R38, R45

R04, R08, R11, R15

R01, R04, R16, R42

R29, R39, R41

R02, R39, R41

R05, R06, R12

R02, R09, R35

R03, R04, R12

R29, R43, R45

R02, R06, R19

R02, R06, R12

$\mathrm{R} 02, \mathrm{R} 27, \mathrm{R} 45$

R02, R12, R16

R02, R12, R16

R02, R17, R37

R04, R27, R35

R03, R09, R41

R02, R09, R35

R09, R27, R37

R27, R37, R39

R27, R37, R43

R03, R05 
Ethnic minorities and asthma research

Appendix 2: Coding framework with topics arranged in order of frequency continued.

Topic

Clinics geographically situated in minority ethnic areas

Thorough use of translators, e.g. for advising on equipment technique

Provide incentives for clinics to participate

Publish in widely read journals to raise awareness

Make it clear that researchers are not coming from the authorities

Give inconvenience payments in instalments

Provide entertainment or gifts for children

Persistence: visiting homes

Use interviewers who can speak the relevant language

Translate invitation letter

Verbal consent if participants illiterate

Use young researchers to target young subjects

Ethics committees require translations to be available

Contribute towards cost of patients' medication

Offer to meet patients at times convenient to them - evenings etc

Telephone participants during study

Check questionnaires with people in the community

Invite patients by letter through their GP

Ensure translator is from the minority group being studied

Include diversity training in qualitative research programmes

Treat ethnic minority patients the same as everybody else

Approach people who are already working in the communities

Raise awareness of the importance of including ethnic minorities

Work with school principals

Provide health education to potential participants

Do not be judgemental about participants' health beliefs or practices

Male interviewer took his wife with him to people's homes

Use techniques to understand cultural differences rather than rules

Department of Health is encouraging people to gain skills in recruiting ethnic minorities

Dept of Health is publicising the benefits of recruiting ethnic minorities

Textbook published to encourage researchers to include ethnic minorities

$\mathrm{NIH}$ demands regular reporting on recruitment

Persistence despite cost

Explain the benefits of participation e.g. children who join studies do better at school

Work with schoolteachers to enrol their students

Give participants credit for their contribution

Use interpreters in focus groups

Work with national collaborations of community groups

Approach community elders to build trust

Careful and appropriate use of focus groups

Explain the personal benefits of participation

Be culturally sensitive in focus groups

Be prepared to hold separate male and female focus groups where appropriate

Be aware of the impact of cultural sub-groups on focus group dynamics

Ensure ethics committees have a representative from communities involved

Including ethnicity in a large database of asthma patients

Use existing language resources

Provide better facilities for translation

Ethnicity recorded in hospital notes so readily available

Work unobtrusively with allied professionals

GP practices employ research assistant to phone participants

Explain the benefits of participation for society at large

Explain that researcher's role is not part of the government

Funding boards have a minority health representative

Advertise using multi-lingual posters

Use symbols in advertisements to suit those who are functionally illiterate

Involve GPs in the development of the study
Mentioned in interview

R09, R41

R05, R41

R09, R37

R18, R39

R35, R37

R41, R43

$\mathrm{R} 02, \mathrm{R} 35$

R02, R03

R02, R11

R04, R11

R05, R09

R05, R45

R08, R18

R09, R27

R09, R35

R09, R35

R12, R19

R15, R19

R16, R23

R01, R18

R19, R27

R29, R41

R29, R39

R37, R45

R37, R45

R38, R39

R01

R01

R01

R01

R01

R02

R02

R02

R02

R02

R04

R04

R05

R05

R06

R06

R06

R06

R06

R07

R07

R07

R07

R09

R11

R12

R12

R12

R13

R13

R15 
L Stirland et al.

Appendix 2: Coding framework with topics arranged in order of frequency continued.

\section{Topic}

Give participants researcher's personal phone number

Advertise in the language relevant to a community

Include photographs of people from relevant community in advertising media

Funding organisations allow for translation costs

Hold focus groups to find out which advertising strategies work

Include awareness of diversity in medical school teaching

Provide spoken study information in DVD or CD format

Include awareness of diversity in NHS training

Ethics committees quote the Amendment of the Race Relations Act

Journal referees expect to see figures for ethnicity of participants

Clinicians phone their patients to invite them personally

Be aware of the content of information material when recruiting for a potentially stigmatising condition

FDA states that a drug must be tested on Afro-American populations before being administered to them

Employ community leaders as study personnel

Personal contact with community leaders

Advertise with posters in places frequented by members of certain community

Broaden the area in which recruitment is taking place

Recruit in a variety of physical locations

Involve people coordinating government aid systems

Rely on enrolment of ethnic minorities working in health service

Combine results from different studies by meta-analysis

Conduct study in area where many people speak the language in question

Ethics committees have question on ethnic minorities

Approach local hospitals or businesses to fund community events

Provide transport to take people from their homes to research centres

Allow for incentives in project budget

Provide incentives for participation even to control subjects

Hold free community events eg. barbecues

Community events are acceptable to funding organisations if they are kept fully informed

Spend time building relationships with community organisations

Pay to advertise in community groups' publications

Only enter people's homes accompanied by a community member

Work with respected local hospitals

Work with other researchers focusing on similar recruitment areas

Approach school administration

Give presentations to school PTAs

Approach community through health professionals already trusted there

Work in GP surgeries

Feed study results back to communities

Persistence: ask for several phone numbers from each participant

Make it clear that researchers are not coming from hospital debt collectors

Employ project staff who are neither doctors nor nurses

Allow easy access to the study clinic

Display photos of the doctors involved in the study clinic

Give participants the option of bringing family members or friends

Provide inexpensive activities for accompanying friends or family

Provide simplified versions of consent forms

Patients attracted to study by opportunity to try expensive drugs

Funding organisations allow for the extra cost of recruiting minorities

Offer incentives to faith organisations for their involvement

Employ people who feel comfortable working in the relevant community

Employ nurses as research personnel

Employ female personnel to promote trust

Advertise in clinical research section of free newspapers

Provide free health screenings
Mentioned in interview

R15

R16

R16

R16

R16

R18

$\mathrm{R} 18$

R18

R18

R18

R19

R23

R23

R29

R29

R29

R29

R29

R29

R29

R29

R29

R30

R35

R35

R35

R35

R35

R35

R35

R35

R35

R35

R37

R37

R37

R37

R37

R37

R37

R37

R38

R38

R38

R38

R38

R38

R38

R42

R43

R43

R43

R43

R43

R43 
Ethnic minorities and asthma research

\section{Appendix 2: Coding framework with topics arranged in order of frequency continued.}

Topic

Hire community centre's rooms

Mentioned in interview

Remember personal details about patients between visits to build rapport

R43

Government policies affect research practices

R43

Involve parents in study, not just giving their consent

R44

Physical presence of researchers

R45

Provide incentives for parents

Meet with children in their schools

Work alongside school health services

School doctors can provide services to even those who do not have insurance

R45

Ask school students to fill in a survey about asthma whether they have it or not, then recruit those who do

Use "passive consent" in high schools

Offer incentives for the class with the highest return of surveys

R45

Work with schoolteachers to understand how best to recruit children

Anonymise survey returns to minimise peer pressure

Ask parents about child recruitment techniques

Provide fun incentives that would not encourage rivalry

Approach high school students first, then check with their parents

Ensure privacy when recruiting in school setting

Employ researchers that teenagers can relate to

Employ research assistant from same ethnic group as community

Students keen to participate if they are allowed to miss lessons

Ask a member of school staff to translate

Provide small gifts for teachers for use in the classroom

Use current school staff or volunteers to recruit students

Persistence: repeated phone calls to GPS

Work at doctor's clinic and mention the doctor's backing

Give small gifts to school nurses who help with recruitment

Ask school nurses to give surveys out to students with asthma

Target schools made up predominantly of ethnic minority students

Play games during interventions

\begin{tabular}{l} 
R45 \\
R45 \\
R45 \\
R45 \\
R45 \\
R45 \\
R45 \\
R45 \\
R45 \\
R45 \\
R45 \\
R45 \\
R45 \\
R45 \\
R45 \\
R45 \\
R45 \\
R45 \\
R45 \\
R45 \\
R45 \\
\hline R45 \\
R45 \\
R45 \\
\hline
\end{tabular}


Appendix 3: List of descriptors from coding, organised in categories.

\section{Trusting Relationships}

\section{- Community groups}

Target people through relevant community groups

Work with national collaborations of community groups

Spend time building relationships with community organisations

Pay to advertise in community groups' publications

Hire community centre's rooms

\section{- Community leaders}

Approach community leaders to help with recruitment

Involve participants and community leaders at the design stage

Approach community elders to build trust

Employ community leaders as study personnel

Personal contact with community leaders

\section{- Faith organisations}

Recruit participants through faith organisations

Offer incentives to faith organisations for their involvement

\section{- Schools}

Work with schoolteachers to enrol their students

Approach school administration

Work with school principals

Meet with children in their schools

Work alongside school health services

School doctors can provide services to even those who do not have insurance

Ask school students to fill in a survey about asthma whether they have it or not, then recruit those who do

Use "passive consent" in high schools

Offer incentives for the class with the highest return of surveys

Work with schoolteachers to understand how best to recruit

children

Ask parents about child recruitment techniques

Provide fun incentives that would not encourage rivalry

Approach high school students first, then check with their parents

Ensure privacy when recruiting in school setting

Students keen to participate if they are allowed to miss lessons

Ask a member of school staff to translate

Provide small gifts for teachers for use in the classroom

Use current school staff or volunteers to recruit students

Give small gifts to school nurses who help with recruitment

Ask school nurses to give surveys out to students with asthma

Target schools made up predominantly of ethnic minority

students

Anonymise survey returns to minimise peer pressure

\section{- Incentives and reimbursement}

Provide entertainment or gifts for children

Provide incentives to subjects for participating

Recompense participants with money, gift certificates

Provide services not otherwise available, eg bronchoscopy

Reimburse participants for travel expenses

Contribute towards cost of patients' medication

Provide incentives for clinics to participate

Provide a meal for participants if they are needed for over an hour
Provide childcare while patients are taking part in the study

Provide patients with their medication

Provide incentives for participation even to control subjects

Hold free community events e.g. Barbecues

Allow for incentives in project budget

Approach local hospitals or businesses to fund community events

Provide health education to potential participants

Provide inexpensive activities for accompanying friends or family

Patients attracted to study by opportunity to try expensive drugs

Give inconvenience payments in instalments

Offer incentives to faith organisations for their involvement

Provide free health screenings

Offer incentives for the class with the highest return of surveys

Provide fun incentives that would not encourage rivalry

Provide small gifts for teachers for use in the classroom

Provide incentives for parents

Give small gifts to school nurses who help with recruitment

- Family involvement

Consider involving other family members in consent process

Give participants the option of bringing family members or

friends

Provide inexpensive activities for accompanying friends or family

Involve parents in study, not just giving their consent

Ask parents about child recruitment techniques

Approach high school students first, then check with their parents

\section{Clear explanations}

Fully explain what to expect from the study

Explain the need for proportional representation

Explain that researcher's role is not part of the government

Make it clear that researchers are not coming from the

authorities

Make it clear that researchers are not coming from hospital debt collectors

\section{- Explain benefits}

Explain the benefits of participation

- for example, children who join studies do better at school

- for example, for the subjects' community

Explain the need for proportional representation

Explain the personal benefits of participation

Explain the benefits of participation for society at large

Feed study results back to communities

\section{- Personal approach}

Long-term relationship building

Provide personal support in the language required, even if the participant speaks English

Invite participants by telephone

Speak personally to invitees

Telephone participants during study

GP practices employ research assistant to phone participants

Give participants researcher's personal phone number

Clinicians phone their patients to invite them personally

Coordinator gets to know the participants personally

Personal contact with community leaders 
Spend time building relationships with community organisations Remember personal details about patients between visits to build rapport

Physical presence of researchers

\section{- Work with trusted professionals}

Work with schoolteachers to enrol their students

Approach patients through their GPs

Work unobtrusively with allied professionals

Involve GPs in the development of the study

Invite patients by letter through their GP

Clinicians phone their patients to invite them personally

Approach people who are already working in the communities

Work with school principals

Approach community through health professionals already

trusted there

Work in GP surgeries

Display photos of the doctors involved in the study clinic

Employ nurses as research personnel

Persistence: repeated phone calls to GPS

Work at doctor's clinic and mention the doctor's backing

- Work with professionals already working in the area

Work with schoolteachers to enrol their students

Work unobtrusively with allied professionals

Involve people coordinating government aid systems

Approach people who are already working in the communities

Work with respected local hospitals

Work with other researchers focusing on similar recruitment

areas

Work alongside school health services

Work with schoolteachers to understand how best to recruit children

Ask a member of school staff to translate

Use current school staff or volunteers to recruit students

Give small gifts to school nurses who help with recruitment

Ask school nurses to give surveys out to students with asthma

\section{- Research staff}

Specialised research employees who focus on recruitment Research colleagues from community being studied act as trusted link

Use interviewers who can speak the relevant language

Use young researchers to target young subjects

Find and use a link person within community

Employ fluent speakers who can understand and explain complex issues

GP practices employ research assistant to phone participants Ensure translator is from the minority group being studied Employ community leaders as study personnel Employ project staff who are neither doctors nor nurses Employ nurses as research personnel

Employ people who feel comfortable working in the relevant community

Employ female personnel to promote trust

Employ researchers that teenagers can relate to

Employ research assistant from same ethnic group as community

\section{Respect}

- Incentives and reimbursement (see Trusting relationships)

- Cultural sensitivity

Validate questionnaires and documents

Be flexible and tailor needs to individual communities

Be culturally sensitive in recruitment

Verbal consent if participants illiterate

Careful and appropriate use of focus groups

Ensure translations are culturally appropriate

Be culturally sensitive in focus groups

Be prepared to hold separate male and female focus groups

where appropriate

Be aware of the impact of cultural sub-groups on focus group dynamics

Oral consent in the patient's language

Develop understanding of cultural differences between researchers and community by communication

Be aware of the content of information material when recruiting for a potentially stigmatising condition

Only enter people's homes accompanied by a community member

Do not be judgemental about participants' health beliefs or practices

Male interviewer took his wife with him to people's homes Use techniques to understand cultural differences rather than rules

\section{Raising awareness}

Publish in widely read journals to raise awareness Include awareness of diversity in NHS training Include diversity training in qualitative research programmes Include awareness of diversity in medical school teaching Raise awareness of the importance of including ethnic minorities Use techniques to understand cultural differences rather than rules

Department of Health is encouraging people to gain skills in recruiting ethnic minorities

Dept of Health is publicising the benefits of recruiting ethnic minorities

Textbook published to encourage researchers to include ethnic minorities

\section{Logistics}

\section{- Advertising}

Advertise in community-specific media Advertise using multi-lingual posters

Use symbols in advertisements to suit those who are functionally illiterate

Advertise in the language relevant to a community Include photographs of people from relevant community in advertising media

Hold focus groups to find out what advertising strategies work Advertise with posters in places frequented by members of certain community

Pay to advertise in community groups' publications

Advertise in clinical research section of free newspapers 


\section{- Language}

Translate consent form

Translate information material

Translate invitation letter

Translate questionnaires

Use interviewers who can speak the relevant language

Provide personal support in the language required, even if the

participant speaks English

Validate questionnaires and documents

Thorough use of translators, eg for advising on equipment

technique

Verbal consent if participants illiterate

Ensure translations are culturally appropriate

Use existing language resources

Provide better facilities for translation

Ethics committees require translations to be available

Oral consent in the patient's language

Employ fluent speakers who can understand and explain

complex issues

Check questionnaires with people in the community

Advertise using multi-lingual posters

Use symbols in advertisements to suit those who are functionally illiterate

Advertise in the language relevant to a community

Ensure translator is from the minority group being studied

Funding organisations allow for translation costs

Provide spoken study information in DVD or CD format

Provide facilities for speakers of languages other than English

Conduct study in area where lots of people speak the language

in question

Provide simplified versions of consent forms

Ask a member of school staff to translate

\section{- Geographical location}

Clinics geographically situated in minority ethnic areas

Advertise with posters in places frequented by members of

certain community

Broaden the area in which recruitment is taking place

Recruit in a variety of physical locations

Conduct study in area where lots of people speak the language

in question

Meet people in their community's geographical area

Provide transport to take people from their homes to research

centres

Work in GP surgeries

Allow easy access to the study clinic

Hire community centre's rooms

Meet with children in their schools

Work at doctor's clinic and mention the doctor's backing

Target schools made up predominantly of ethnic minority students

- Incentives and reimbursement (see also Trusting relationships)

- $\quad$ Budgeting

$\mathrm{NIH}$ accepts provision for incentives within grant budgets

Funding organisations allow for translation costs

Allow for incentives in project budget
Approach local hospitals or businesses to fund community events

Funding organisations allow for the extra cost of recruiting minorities

- $\quad$ Funding bodies

$\mathrm{NIH}$ may withdraw funding if targets are not met

Private funding bodies may also penalise for excluding ethnic minorities

Funding boards have a minority health representative

Funding organisations allow for translation costs

Community events are acceptable to funding organisations if they are kept fully informed

Funding organisations allow for the extra cost of recruiting minorities

\section{- Pooling}

Including ethnicity in a large database of asthma patients

Combine data from different sites

Combine results from different studies by meta-analysis

\section{- Persistence}

Persistence: repeated phone calls

Persistence visiting homes

Persistence despite cost

Telephone participants during study

Persistence: ask for several phone numbers from each participant Persistence: repeated phone calls to GPs

\section{Policy}

\section{Government policies}

$\mathrm{NIH}$ accepts provision for incentives within grant budgets $\mathrm{NIH}$ demands regular reporting on recruitment $\mathrm{NIH}$ makes it compulsory to recruit ethnic minorities $\mathrm{NIH}$ may withdraw funding if targets are not met $\mathrm{NIH}$ demands relevant representative samples from communities It is difficult to get away from representing minorities $\mathrm{NIH}$ guidelines on recruitment and representation work Ethics committees quote the Amendment of the Race Relations Act

FDA states that a drug must be tested on Afro-American populations before being administered to them Government policies affect research practices Department of Health is encouraging people to gain skills in recruiting ethnic minorities

Department of Health is publicising the benefits of recruiting ethnic minorities

\section{- Ethics committees}

Ethics committees have question on ethnic minorities Ensure ethics committees have a representative from communities involved

Ethics committees quote the Amendment of the Race Relations Act

Ethics committees require translations to be available 